\title{
Global and China temperature changes associated with the inter-decadal variations of East Asian summer monsoon advances
}

\author{
QIAN WeiHong ${ }^{1 *}$, LIN Xiang $^{2} \&$ ZHU YaFen ${ }^{1}$ \\ ${ }^{1}$ Department of Atmospheric and Oceanic Sciences, School of Physics, Peking University, Beijing 100871, China; \\ ${ }^{2}$ Institute of Climate System, Chinese Academy of Meteorological Sciences, Beijing 100081, China
}

Received February 20, 2012; accepted May 4, 2012; published online July 10, 2012

\begin{abstract}
The modern atmospheric observation and literatural historical drought-flood records were used to extract the inter-decadal signals of dry-wet modes in eastern China and reveal the possible relationship of global and China temperature changes associated with the East Asian summer monsoon advances. A climate pattern of "wet-north and dry-south" in eastern China and cool period in China and globe are associated with the strong summer monsoon that can advance further to the northernmost part in the East Asian monsoon region. On the contrary, a climate pattern of "dry-north and wet-south" in eastern China and a warm period in China and globe are associated with the weaker summer monsoon that only reaches the southern part in the region. An interdecadal oscillation with the timescale about 60 years was found dominating in both the dry-wet mode index series of the East Asian summer monsoon and the global temperature series after the secular climate states and long-term trend over inter-centennial timescales have been removed.
\end{abstract}

East Asia, summer monsoon, inter-decadal timescale, dry-wet mode, global temperature change

Citation: Qian W H, Lin X, Zhu Y F. Global and China temperature changes associated with the inter-decadal variations of East Asian summer monsoon advances. Chin Sci Bull, 2012, 57: 3923-3930, doi: 10.1007/s11434-012-5318-5

The global-mean temperature for the last hundred years was proposed as a main index for climate change published in IPCC Reports since 1990. The rising rates of the globalmean temperatures during the last hundred years were about $0.45,0.45,0.60$ and $0.74^{\circ} \mathrm{C}$ as reported from the four different IPCC Reports, respectively [1]. During the global cool period in 1950-1970, studies focused on how the global climate will become cooler [2]. In that cool period, Broecher [3] was one of the earliest scientists who were concerned that global warming may appear. Since the 1980s, the global warming has become a hotter topic in the research of climate change along with the increasing in global-mean temperature [4].

The global-mean temperature and its change are derived by summing from all the continents and oceans in the world. The temperature change in China is also the key content in the "China's National Assessment Report on Climate

\footnotetext{
*Corresponding author (email: qianwh@pku.edu.cn)
}

Change" [5]. Global temperature change has not only the warm and cool periods of temporal variation, but also the regional spatial distributions. East China is a typical monsoon area. In the East Asian region, the climate prevails by the cold-dry westerly airflow in winter while warm-wet southerly airflow in summer, so that an annual cycle of monsoon climate forms. Besides, both the local intensities and extent of northward advances of the East Asian summer monsoon (EASM) show noticeable inter-annual and interdecadal variations. Such variability of EASM is related to that of the precipitation and temperature in China, for example, recent study indicated the inverse correlation between the numbers of rainy days and hot days on the interannual and inter-decadal timescales [6]. Therefore, two climate issues need to be further explained. Firstly, how the intensities of monsoon are related to summer and annual mean precipitation and temperature in different regions in China. Secondly, what are the relationships between summer rainfall/temperature variations and the summer mon- 
soon intensities at the inter-decadal timescale? The modern atmospheric observations and historical drought-flood records are used to answer above two questions in this study.

\section{Data and methods}

Five datasets with different analysis methods were used in study. The first is the US Climate Prediction Center (CPC) Merged Analysis of Precipitation (CMAP) and it is derived from http://www.esrl.noaa.gov/psd/, during 1979-2007 with spatial resolution of $2.5^{\circ}$ grids [7]. The CMAP data is used to identify the dry-wet seasonal alternation areas in the Eastern Hemisphere.

The second dataset derived from Beijing Climate Center (BCC) is the observation of the precipitation at 160 stations for 1951-2008. The spatial distribution of precipitation percentages and dry-wet patterns are obtained. In addition, four long-term series of summer/annual precipitation and temperature for about a century are derived from the Beijing and Macao stations. The local phase relationships for the summer and annual precipitations (and temperature) between South China and North China can be identified from the inter-decadal timescale using above observations.

The third dataset is the monthly winds and specific humidity [8], derived from the website of NCEP/NCAR (http:// www.esrl.noaa.gov/psd/data/gridded), with the grids of 2.5 degrees from 1948 to 2008. The monthly vertical-weighted specific humidity $q$ and moisture transport at each grid over the lower troposphere $(1000,925,850,700,600$ and 500 $\mathrm{hPa}$ ) are calculated [9] to examine the inter-decadal variation of moisture transport over the Eastern Hemisphere.

The fourth dataset is the dry-wet modes constructed by Wang [10] based on the local governmental literature that described the summer (May to September) climate with five grades of very dry (drought), dry, normal, wet and very wet (flood) over eastern China in the historical period from AD 950 to 1980 . By Combining the Wang's millennial dry-wet modes and the spatial distributions of summer precipitation percentages in eastern China for 1951-2008, a dry-wet mode (DWM) index series from AD 950 to 2008 was reconstructed in our previous study [11]. The signals of interannual, decadal and inter-decadal timescale variations can be detected from the time series but the centennial timescale variation cannot be trusted since literatures described by people from different generations.

The fifth type of data is the China annual-mean temperature in the last century [12] and the global-mean temperature based on the Mann's series reconstructed for the past two millennia [13], including temperature change in decadal, inter-decadal and centennial timescales. In the Mann's series, two long-term mean climate states were detected, namely the Medieval Warm Period (MWP) and Little Ice Age (LIA), and a long-term trend, the recent Global Warming Period (GWP). Two turning time points separated three long-term periods can be determined at the 1440s and the 1840s [14]. The climate state temperatures dropped $0.24^{\circ} \mathrm{C}$ from the MWP to LIA periods. During the recent GWP for 1850-2008, the global-mean temperature rose $0.44^{\circ} \mathrm{C}$ per century. What caused the climate change may be different from various timescales. In order to analyze the relationship between the global-mean temperature change and the drywet mode variation in eastern China, two long-term climate states from the MWP and LIA and a long-term trend for the period of the GWP have been removed [14]. After removing climate states and the long-term trend, a temperature anomaly series was derived and used to find its decadal and interdecadal signals.

\section{Dry-wet variations in the subtropical monsoon region}

The monsoon research has a long history, but the identification of global monsoon regions has not. In the 1970s, monsoon area was identified by the reversal of surface wind directions with seasons [15]. In the 1980s, Webster [16] proposed a monsoon definition by which monsoon regions should experience not only the seasonal reversal of wind direction, but also the seasonal dry-wet alternation. Six monsoon regions in the globe have been identified according to such definition [16]. During the period from 2000 to 2002, considering the seasonal reversal of wind directions, dry-wet alternation and crossing-equatorial airflow, Qian et al. $[17,18]$ proposed a definition that the monsoon is a seasonal polarward expansion of tropical water vapor centers driven by the crossing-equatorial airflow. Finally, they gained a map of the global monsoon regions. At the same time, Trenberth et al. [19] proposed the global monsoon as the large-scale overturning of atmosphere circulation with the season. After that, Li and Zeng [20] proposed another global monsoon definition with an index of the dynamical normalized seasonality based on the wind seasonal variations.

Seasonally, two characteristic time points were found in the pentads 8 and 44 at which zonal-averaged atmospheric variables at the $850 \mathrm{hPa}$ level, including meridional and zonal winds, geopotential height, temperature and precipitation, reaches climate maxima of the annual cycle [21]. At the pentad 8 (or 44), all variables reach their maximum in the Southern (or Northern) Hemisphere, which is one month later than the time when sunlight irradiate directly on the tropic of Capricorn (Cancer).

Using the CMAP precipitation, dry-wet alternation between the pentads 8 and 44 in the Eastern Hemisphere is plotted in Figure 1. In the Northern Hemisphere, these alternation regions have experienced the climate precipitation from less than $4 \mathrm{~mm} / \mathrm{d}$ in the pentad 8 to more than $4 \mathrm{~mm} / \mathrm{d}$ in the pentad 44 and reversed change has been observed in the Southern Hemisphere [22]. Along the equatorial zone 


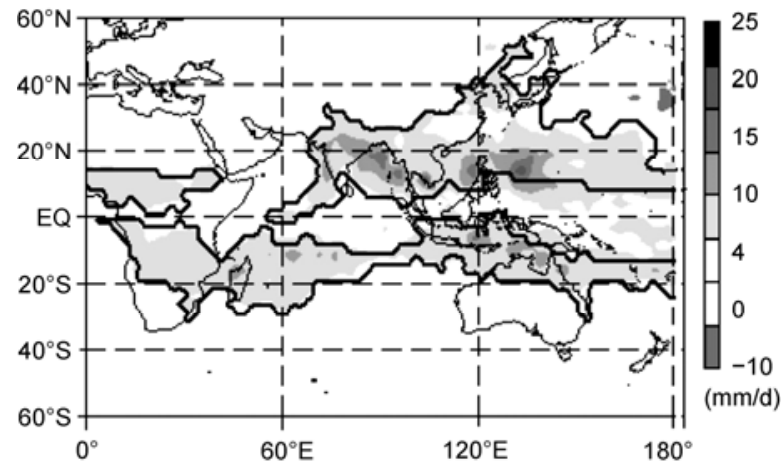

Figure 1 Monsoon region identified by dry-wet alternation in the Eastern Hemisphere. The heavy solid line covers the region with the climate dailymean precipitation more (less) than $4 \mathrm{~mm} / \mathrm{d}$ at the pentad 44 and less (more) than $4 \mathrm{~mm} / \mathrm{d}$ at the pentad 8 in the Northern (Southern) Hemisphere, shading areas indicate the difference of precipitation $(\mathrm{mm} / \mathrm{d})$ between the pentads 44 and 8 .

$\left(10^{\circ} \mathrm{S}-10^{\circ} \mathrm{N}\right)$, the climate daily-mean precipitation is always more than $4 \mathrm{~mm} / \mathrm{d}$ so that the equatorial zone is covered by water vapor all the year without dry-wet alternation. In the subtropical regions over the two hemispheres, the solid lines cover the seasonal dry-wet alteration regions to which the summer monsoon airflows convey the water vapor at the lower troposphere from the tropical zone. The largest area of dry-wet alternation along south-north orientation exists in the region between Asia and Northwest Pacific. The northern part of South China Sea and eastern China are located in the region of dry-wet alternation as in East Asia. A monsoon marginal zone is defined as the area where the monsoon prevails only in some years, but not every year. In Asia, the north marginal zone of dry-wet alternation is oriented eastward from the north part of India to Southwest China, and further to North China and Northeast China. Besides, another marginal-north zone of dry-wet alternation is located in the tropical North Africa.

Climate average precipitation and standard deviation in summer (May to September) are calculated by using every one of total 160 stations data in China for 1951-2008. For each station and each year, the dry-wet grade from 1 to 5 was determined by the summer precipitation departure [11]. The grades 1-2 indicate the positive departures, the grades 4-5 indicate the negative departures and grade 3 means the normal precipitation in the summer. Six dry-wet modes (DWM thereafter) of spatial distribution were determined from the summer precipitation grades in eastern China [11], and each of years from 1951 to 2008 has been classified into one of the six modes. Six modes include precipitation departures of the (1) below normal in the whole eastern China, (2) below normal in northern China and above normal in southern China, (3) above normal over the Yangtze River basin and below normal in South and North China, (4) above normal over the whole eastern China, (5) above normal in northern China and below normal in southern China, and (6) below normal over the Yangtze River and above normal in South and North China, respectively. Three precipitation patterns used in National Climate Center and the dipole/tri-pole patterns investigated by Ding et al. [23] can also be noted in the above dry-wet modes. Considering the close relationship between East Asian summer monsoon and precipitation in East China, the values of the above six modes can be treated as an index of East Asian summer monsoon (EASM). Recent research [11] has already indicated that the DWM index well reflect the spatial characteristic of precipitation in East China, with a reversal phase existing between the northern and southern China. In contrast, the other EASM indices mainly reflect the variability and characteristics of precipitation in the Yangtze River valley alone. As one of EASM indices, the DWM index can represent the intensity and northward advance of EASM. The high value period of DWM index means that the EASM airflow can convey more moisture to the northern China and enhance more local precipitation in there, while the low value period of DWM index is correspond to the less precipitation in northern and more precipitation in southern China.

From 1951 to 2008, the DWM index has a trend of long-term decreasing with a dry tendency in northern China and a wet tendency in southern China [11]. After removing the long-term trend, the variations of DWM index at inter-annual, decadal, and inter-decadal timescales can be observed. At the inter-decadal timescale, two periods of 1956-1966 and 1992-2002 are chosen as typical decades with averaged DWM index values of 4.18 and 2.36, respectively. The composites of summer precipitation percentages in two periods were shown in reference [11]. For the period of 1956-1966, more precipitation occurred from Southwest China to North China and Northeast China, i.e. along the northern marginal zone of dry-wet alternation as shown in Figure 1, while less precipitation occurred over the south of mid-low Yangtze River. For the period of 1992-2002, the anomalous distribution of summer precipitation with the "dry-north and wet-south" pattern was just opposite to the first period [24].

Every year, the dry-wet modes are determined by the strength of the southerly monsoon airflow or moisture transport. Because of this relationship, the effects of largescale circulation can be identified by the dry-wet modes. Moisture transport from the lower troposphere based on the monthly winds and specific humidity at the levels of 1000 , $925,850,700,600$ and $500 \mathrm{hPa}$ and at 2.5 by 2.5 latitudelongitude grids were calculated $[9,11]$. Each of six dry-wet modes can be explained by the composite moisture transport. In this paper, Figure 2 shows the composites of low-troposphere moisture transports averaged from the surface to 500 hPa for two periods of 1956-1966 and 1992-2002 in summer. During the decade of "north-wet and south-dry" ("north-dry and south-wet") pattern of summer precipitation in eastern China, stronger (weaker) southwesterly airflow with more (less) moisture transports cover large part of 

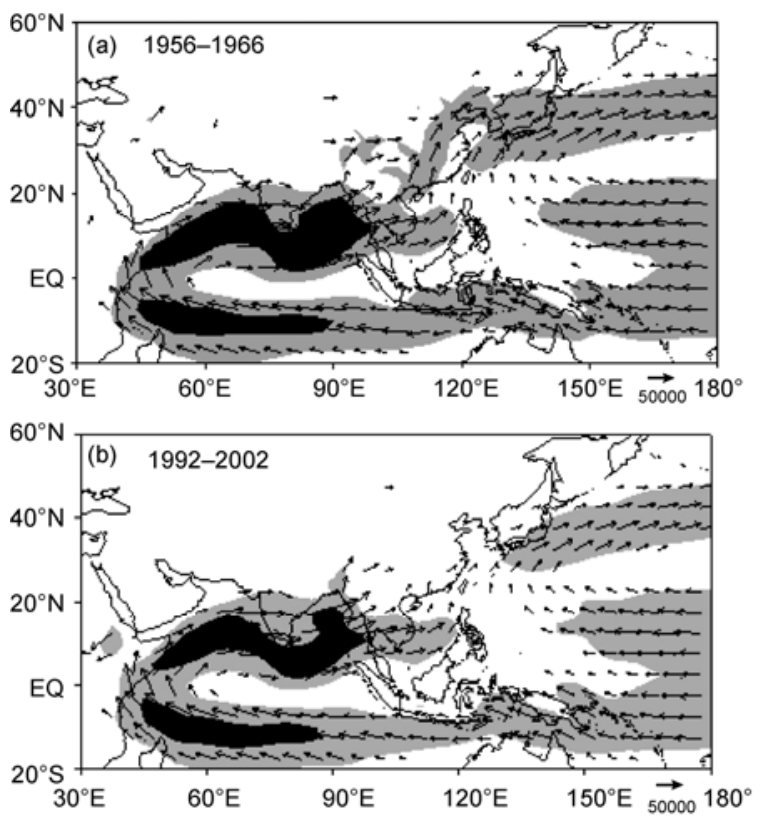

Figure 2 Composites of low-troposphere moisture transports from the surface to $500 \mathrm{hPa}$ based on two decades (a) 1956-1966 and (b) 19922002. Vectors indicate the direction of moisture transports, heavy and light shades indicate that moisture transports are greater than 60000 and 30000 $\mathrm{g} \mathrm{m}^{-1} \mathrm{~s}^{-1}$, respectively.

China and northwest Pacific region. It is clear to note that more moisture transports can be found along the northern marginal zone of dry-wet alternation from Southwest China to North China and Northeast China for the decade 19561966 as comparison to the decade of 1992-2002. The inter-annual and inter-decadal variations of moisture transports in their intensity and location are extensively located along the northern marginal activity zone in northern China [25]. In Figure 2, strong moisture transport can be found over South Asia and North China so that it can well explain the consistence between summer precipitation anomalies in India and North China [26]. Their differences, however, are that the former reflects tropical monsoon intensity while the latter denotes the extent change of EASM advances.

\section{Temperature and precipitation in the subtropical region}

In order to examine the relationships among the moisture transport, precipitation and temperature in the EASM region in a more actual way and from longer time span, observational data in China are also used. Figure 3 shows the series of summer (JJA) and annual-mean precipitation as well as temperature at the stations of Beijing and Macao in the last century. To analyze the inter-decadal variation, the longterm trends have been removed from the series and then the high frequency variation have also been filtered out from the departure series using 9-points running averages. The two stations are located in the region of East Asian summer
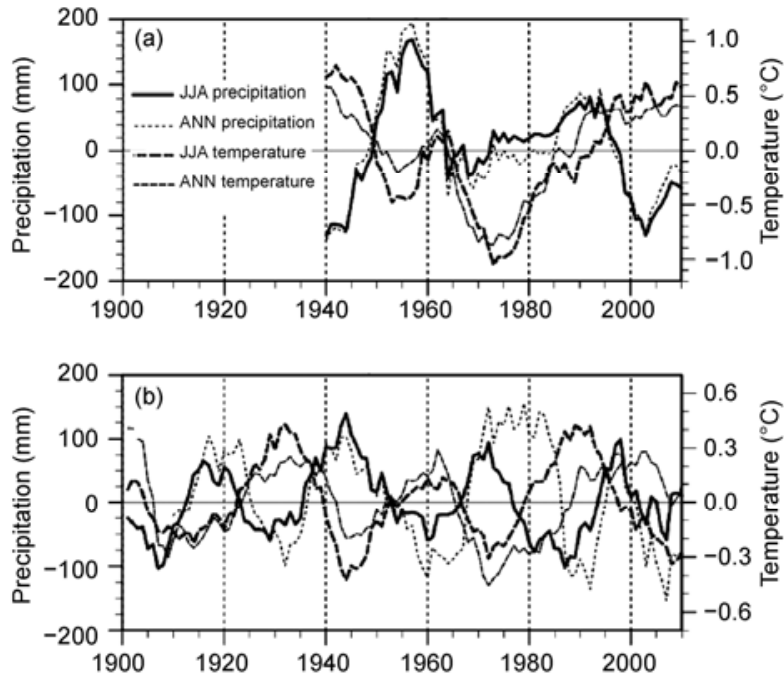

Figure 3 Summer (JJA) precipitation departures (heavy solid line), annual-mean precipitation departures (point line), summer (JJA) temperature departures (heavy dashed line), and annual-mean temperature departures (light dashed line) at (a) the Beijing station for 1940-2010 and (b) the Macao station for 1901-2010 after their long-term trends removed and interannual variability removed by 9 -point running average (unit: ${ }^{\circ} \mathrm{C}$ ).

monsoon, because the Beijing station $\left(116.46^{\circ} \mathrm{E}, 39.92^{\circ} \mathrm{N}\right)$ is near its northern marginal zone and the Macao station $\left(113.5^{\circ} \mathrm{E}, 22.2^{\circ} \mathrm{N}\right)$ in its southern part. It is clearly found from the time series that the summer precipitation and summer temperature variations at the inter-decadal timescale at Beijing as a station in the northern marginal zone of subtropical monsoon can well represent annual-mean ones. The summer precipitation and summer temperature variations at the inter-decadal time scale at the Macao station is also consistent with annual-mean ones, only except during 1970-1980 when the summer precipitation and summer temperature lead annual-mean ones in their phases. Some features can be noted from these curves in that they all have inter-decadal variations and the precipitation has an opposite phase relation with temperature at the same station, i.e. more (less) precipitation accompanying with low (high) temperature. In Figure 3, the amplitude of the Beijing temperature variation at the inter-decadal timescale is about $2{ }^{\circ} \mathrm{C}$ while the amplitude of the Macao temperature variation is near $0.7^{\circ} \mathrm{C}$, so that the amplitude of temperature variations in northern China is about 3 times larger than that in southern China. It can be inferred that in China as a whole the larger contribution of temperature variations at the interdecadal timescale comes from the ones in northern China.

As early as the twentieth century, a complete observation was lacking at the Beijing station. Therefore, we focus on the analysis of temperature and precipitation variations at the inter-decadal timescale for the Beijing station since 1940. A out-of-phase correspondence between the temperature and precipitation can be observed that less summer or annual-mean precipitation was accompanied with higher summer or annual-mean temperature in the 1940s and in 
recent decade, more summer or annual-mean precipitation was accompanied with lower summer or annual-mean temperature in the $1950 \mathrm{~s}$, and lower summer or annual-mean temperature was accompanied with more summer precipitation and near normal annual-mean precipitation in the 1970s. Due to limit of short period of this observational series in Beijing station, the phase relationship of variations between temperature and precipitation was analyzed instead of the calculation of their correlation.

Observation of temperature and precipitation can be derived from the Macao station for the last century. The more summer or annual-mean precipitation accompanied with lower summer or annual-mean temperature is observed in the 1910s, 1940s and near the year 1970 while the less summer or annual-mean precipitation accompanied with higher summer or annual-mean temperature is observed near the years of 1930 and 1960 and the decade of 1980s. The correlation coefficient between the summer precipitation and summer temperature is -0.54 for the original series and -0.56 for the series of 9-point running average. Both have reached the 0.01 significance levels. After filtering out high frequency variations by 9-point running average, their correlation values between annual-mean precipitation and annual-mean temperature, summer precipitation and annualmean precipitation, summer temperature and annual-mean temperature, are $-0.67,0.52$ and 0.51 , respectively .

All the facts mentioned above indicate that monsoon advance, temperature and precipitation variations as well as their interaction should be considered to better understand the climate change in subtropical monsoon regions. At the long-term change, the Beijing precipitation had a decreasing trend since the 1950s but the long-term trend is not clear in the Macao precipitation series. Dry and wet differences between northern and southern China in the monsoon region can be indicated by above normal precipitation at Beijing and below normal precipitation at Macao in the 1940s, and below normal precipitation at Beijing and above normal precipitation at Macao from the 1950s to the early 1960s. Other three periods with the opposite phase relations can be found near the years of 1970, 1990 and 2000. At the interdecadal timescale, the variations of summer monsoon precipitation in northern China and southern China are basically opposite in phases while another opposite phase relationship exists between local temperature and precipitation.

Two periods of 1951-1966 and 1992-2002 chosen in Figure 2 show the opposite phase inter-decadal variations of precipitation and temperature as indicated by local records of Beijing and Macao in Figure 3. A scheme can be described: stronger (weaker) monsoon airflow from tropical Indian Ocean, more (less) moisture transport reaching northern China, above (below) normal precipitation in northern China, below (above) normal precipitation in southern China, below (above) normal temperature in northern China, above (below) normal temperature in southern China.

\section{Monsoon advance and temperature variation}

The relationships among precipitation, temperature, monsoon advance, and moisture transport have been revealed for local climate of Beijing and Macao in section 3. Now, we can further examine the changes in the East Asian monsoon advance, the China annual-mean temperature and the global-mean temperature from the inter-decadal timescale. Figure 4 shows the relationship between the China annualmean temperature series [12] and the summer monsoon DWM index series [11] in the recent century. Since 1880, the DWM index series in eastern China (or East Asian) monsoon region experienced a long-term decreasing trend, so it implies that the moisture transport coming from tropical Indian Ocean and precipitation in northern China have been reduced, and the annual-mean temperature in the whole China has increased. In the last century, several anomalous events of climate oscillations can be clearly observed from the DWM index series and the annual-mean temperature series in China. The weakest points in the anomaly series of MDW index with the value from -2 to -3 and high temperature occurred in the late 1920s (Figure 4).

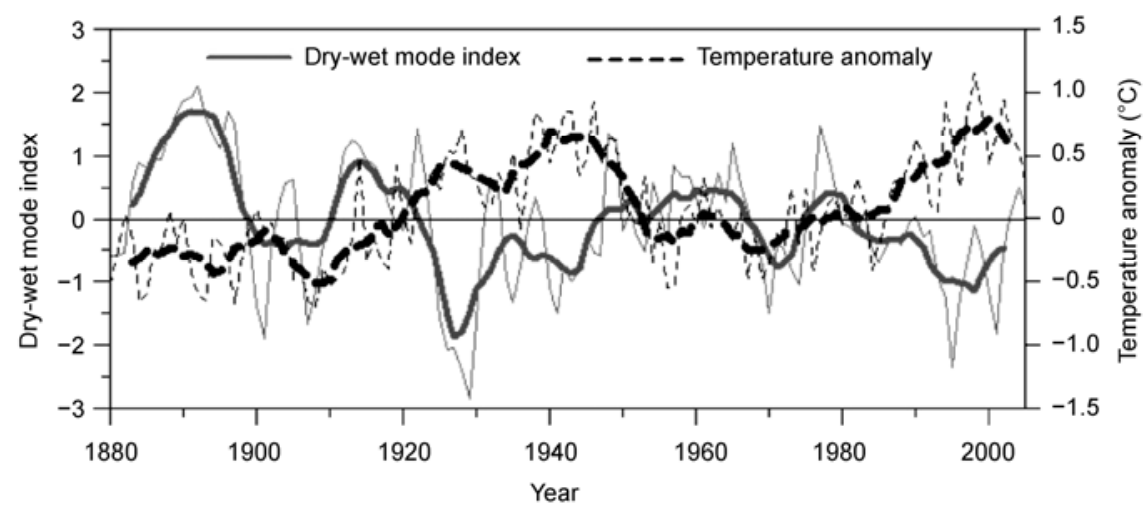

Figure 4 The dry-wet mode index series in eastern China derived from the 7-point (thin solid line) and 21-point (thick solid line) running averages, China annual-mean temperature series (thin dashed line) and its low frequency signal derived from the 7-point running average (thick dashed line, unit: ${ }^{\circ} \mathrm{C}$ ) from 1880 to 2005 . 
In that period, the severe dry climate event leading to locust swarms caused widespread crop failure and persistent famine in northern China [27]. In the 1990s, the low value in DWM index series and relative high temperature (warm period) resulted in long-term low runoff in the Yellow River and persistent dry climate in northern China. In the late 1930 to 1940 s, another warm period was also accompanied with sustained low value in DWM index series. An internal connection between the extent of summer monsoon advance in eastern China and the annual-mean temperature of China at the long-term trend and inter-decadal timescale can be found in Figure 4. A corresponding relationship can be clearly presented that the China annual-mean temperature's decrease/increase depends on whether the summer monsoon northward advance can reach the northern marginal zone in China or not. As seen in Figure 4, an oscillation with the timescale of about 60 years from the DWM index series existed by high value periods in 1880-1920 and 1945-1980, and low value periods in 1920-1945 and since 1980, respectively. Also as seen in Figure 4 by the dashed line, an oscillation with the timescale of about 60 years from the China annual-mean temperature series existed by cold periods in 1880-1920 and 1953-1980, and warm periods in 1920-1950 and since 1985, respectively. At the 60-year timescale, the opposite phase relation of their oscillations is clearly seen by comparison between the monsoon DWM index series and the China annual-mean temperature series. At the decadal timescale, however, their variation phases are not always opposite, such as in the decade near the year 1970 , so that the climate change in the decadal timescale may be complex [28].

As a discussion, Figure 5 shows the comparison between the millennial DWM index series in eastern China [11] and the global-mean temperature [14] at the inter-decadal timescale. The larger value of DWM index series in Figure 5(a) indicates that above-normal precipitation occurred in northern

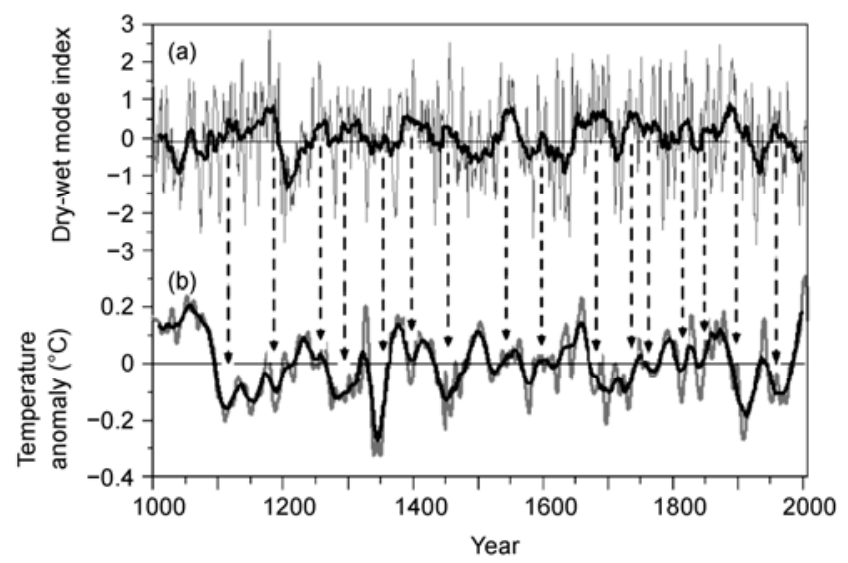

Figure 5 (a) Dry-wet mode index series by the 7-point (light line) and 21-point (thick line) running averages; (b) the global-mean temperature (gray line) and its 21-points running average series (thick line) after removing the centennial-scale trend and climate states, the dashed arrows connect the fluctuations between two curves.
China is accompanied with the summer monsoon airflow extending to northern areas in East Asia. In Figure 5(b), the inter-decadal variation of the global-mean temperature with its amplitude about $0.3^{\circ} \mathrm{C}$ existed in the millennial series after removing its climate states and long-term trend. In the last millennia, an opposite phase oscillation between the two series of global-mean temperature and the DWM index series existed at the inter-decadal timescale. Two series have a correlation coefficient of -0.11 , reaching the 0.01 significant levels. In Figure 5, the arrows connect the corresponding pairs of high values of DWM index series and the low values of the global-mean temperature series. There are at least 16 fluctuations from two series in the last millennia. At a period when the summer monsoon advance further north than normal, the global-mean temperature is lower than normal except for some cases with a phase shift. The strongest cold period at the inter-decadal timescale occurred near the years 1900 and 1960 in the recent 200 years when the summer monsoon further northward advance was about 10 years earlier than the global-mean temperature variation. In the last 50 years, the extent of East Asian summer monsoon has withdrawn southward and accompanied with the rising global-mean temperature.

Recently, a conclusion made by Ge et al. [29] with their study on the China climate change in the last 2000 year indicated that the "dry-north and wet-south" is main pattern of precipitation in eastern China under the warm climate state. The opposite phase relationships of the oscillations were revealed among the DWM index series, the China annualmean temperature and the global-mean temperature at the inter-decadal timescale. The relationships obtained have not distinguished by the various climate states but those warmcold climate states have been removed from the globalmean temperature series. It is needed to further study their climate pairs such as cold-dry, cold-wet, warm-dry and warm-wet patterns.

\section{Discussion and conclusion}

This paper comprehensively applied the modern atmospheric observations and historical literatural records to extract the inter-decadal signal of summer monsoon dry-wet modes in eastern China and revealed the oscillation phase relationships among the extent of summer monsoon advance in East Asia, the China annual-mean temperature and the global-mean temperature. A main result is that the above (below ) normal moisture can reach northern China and the anomalous climate pattern named as "wet-north and drysouth" ("wet-south and dry-north") is accompanied in eastern China, which is also correspond to below (above) normal temperature in China and globe at the inter-decadal timescale as the summer monsoon advanced more (less) northward.

With the several climate series given in this paper, some 
possible relationships can be further discussed at interdecadal timescale.

(1) The relationship between the above (below) normal annual-mean temperature in China and the weaker (stronger) monsoon airflow in East Asia. The subtropical monsoon in East Asia not only has its local (South China, Yangtze River and North China) intensity variations but also has its extent variations from inter-annual and inter-decadal timescales. At the tropical monsoon region, such as in South Asia, the strong summer monsoon accompanies local above-normal precipitation. In the East Asian subtropical region, however, precipitation is caused mainly by the system of monsoon trough. Climatologically, after the summer monsoon onset in the South China Sea, the subtropical monsoon trough advances northward gradually and reaches the monsoon marginal zone at about the pentad 44 [30]. In some years or decades, the subtropical monsoon trough was stable along the Yangtze River and the summer monsoon airflow can only reach south edge of northern marginal zone, so that the above-normal precipitation could be observed in the Yangtze River basin with below-normal precipitation in northern part of China, such as during the decade 1992-2002 with the below-normal precipitation in northern China and above-normal temperature in China. During the decade 1956-1966, the strong summer monsoon airflow reached northern China and accompanied the above-normal precipitation in northern China and below-normal temperature in China. The China temperature variation is associated with the precipitation distribution and EASM advance.

(2) The relationship between the heating contrast and monsoon intensity. At first, one of the reasons of the monsoon airflow formation should be attributed to the heating contrast and pressure difference between the adjacent land and sea. Under the background of the global warming, the warming in the Northern Hemisphere is greater than that in the Southern Hemisphere, the warming in the high latitudes is greater than that in the low latitudes, and the warming in the continent is greater than that over the ocean so that the greatest warming should exist in the Eurasian continent and the warming tendency is greater in northern China than that in the southern China [31]. The question how the above fact is related to all indices of the East Asian summer monsoon indicates a decreasing trend in the recent decades under the present warming climate? The horizontal scale of monsoon airflow reach thousands of kilometers and its vertical overturning circulations occupy the entire troposphere. The intensity variations of monsoon at inter-annual and interdecadal timescales are just the anomalies in atmospheric circulation, which is caused by the adjacent land-sea heating contrast. By speculation, we use the anomalies of thermal wind to explain the decreasing summer monsoon. In the Asian region, anomalous warming in the high latitudes is greater than that in the low latitudes so that the anomalous thermal wind is easterly which reduce the westerly airflow of south Asian summer monsoon. On the other side, warm- ing tendency is greater in the Asian continent than that in the eastern Pacific Ocean, which implies the anomalous thermal wind reducing the southerly monsoon airflow in the East Asian region. This heating contrast can explain the weakening summer monsoon in its intensity and the shrunken extent during the EASM seasonal advance.

(3) The relationship between the DWM index series in eastern China and the global-mean temperature at the inter-decadal timescale. The summer DWM index in eastern China reflects the expansion of the extent of East Asian monsoon. The inter-decadal anomalous warming over the Asian continent may explain the decreasing summer monsoon intensity in East Asia through the anomalous thermal wind. Similarly, the inter-decadal anomalous warming over the global high latitudes and continents may also explain the decreasing summer monsoon intensity in the globe through the anomalous thermal wind. There are six major monsoon regions in the world. Whether the other five monsoons also weakened in recent decades need to be examined and analyzed by further studies.

The authors thank the anonymous reviewers for their helpful suggestions. This work was supported by the Strategic Priority Research Program of the Chinese Academy of Sciences (XDA0509400) and the National Natural Science Foundation of China (40805036).

1 Zhao Z C, Wang S W, Luo Y. Assessments and projections of temperature rising since the establishment of IPCC (in Chinese). Adv Clim Change Res, 2007, 3: 183-184

2 Dickinson R E. Infrared radiative heating and cooling in venusian mesosphere. I: Global mean radiative equilibrium. J Atmos Sci, 1972, 29: 1531-1556

3 Broecher W S. Climatic change-Are we on brink of a pronounced global warming? Science, 1975, 189: 460-463

4 Solomon S, Qin D, Manning M, et al. Climate Change 2007: The Physical Science Basis. Contribution of Working Group I to the Fourth Assessment Report of the Intergovernmental Panel on Climate Change. Cambridge: Cambridge Univ Press, 2007. 1-996

5 Li X Y, Qin D H, Li J Y, et al. China's National Assessment Report on Climate Change (in Chinese). Beijing: Science Press, 2007. 1-422

6 Ding T, Qian W H, Yan Z W. Changes in hot days and heat waves in China during 1961-2007. Int J Climatol, 2010, 30: 1452-1462

7 Xie P P, Arkin P A. Global precipitation: A 17-year monthly analysis based on gauge observations, satellite estimates, and numerical model output. Bull Amer Meteorol Soc, 1997, 78: 2539-2558

8 Kalnay E, Kanamitsu M, Kistler R, et al. The NCEP/NCAR 40-year reanalysis project. Bull Am Meteorol Soc, 1996, 77: 437-471

9 Qian W H, Lin X, Zhu Y F, et al. Climatic regime shift and decadal anomalous events in China. Clim Change, 2007, 84: 167-189

10 Wang S W, Zhao Z C, Chen Z H, et al. Drought/flood variations for the last two thousand years in China and comparison with global climatic change. In: Ye D Z, Fu C B, Chao J P, et al., eds. The Climate of China and Global Climate. Beijing: China Ocean Press; Berlin Heidelberg/New York: Springer Press, 1987. 20-29

11 Qian W H, Zhu Y F, Tang S Q. Reconstructed index for summer monsoon dry-wet modes in East Asian for the last millennium. Chin Sci Bull, 2011, 56: 2075-2082

12 Wang S W, Ye J L, Gong D Y, et al. Construction of mean annual temperature series for the last one hundred years in China (in Chinese). Quart J App Met, 1998, 9: 392-401

13 Mann M E, Zhang Z H, Hughes M K, et al. Proxy-based reconstructions of hemisphere and global surface temperaure variations over the 
past two millennia. Proc Natl Acad Sci USA, 2008, 105: 1225713252

14 Qian W H, Lu B. Periodic oscillations in millennium global-mean temperature and their causes. Chin Sci Bull, 2010, 55: 4052-4057

15 Ramage C S. Monsoon Meteorology. New York: Academic Press, 1971. 1-296

16 Webster P J. The Elementary Monsoon. In: Fein J S, Stephens P L, eds. Monsoons. New York: A Wiley-IntereScience Publication, 1987. 3-32

17 Qian W H. Dry/wet alternation and global monsoon. Geophys Res Lett, 2000, 27: 3679-3682

18 Qian W H, Deng Y, Zhu Y F, et al. Demarcating the worldwide monsoon. Theor Appl Climatol, 2002, 71: 1-16

19 Trenberth K E, Stepaniak D P, Caron J M. The global monsoon as seen through the divergent atmospheric circulation. J Clim, 2000, 13: 3969-3993

20 Li J P, Zeng Q C. A new monsoon index and the geographical distribution of the global monsoons. Adv Atmos Sci, 2003, 20: 299-302

21 Qian W H. Atlas of Climate Change and Extreme Climate Events in China (in Chinese). Beijing: China Meteorological Press, 2011. $1-259$

22 Qian W H, Tang S Q. Identifying global monsoon troughs and global atmospheric centers of action on a pentad scale (in Chinese). Atmos Ocean Sci Lett, 2010, 3: 1-6

23 Ding Y H, Wang Z Y, Sun Y. Inter-decadal variation of the summer precipitation in East China and its association with decreasing Asian summer monsoon. Part I: Observed evidences. Int J Clim, 2008, 28: 1139-1161

24 Sun L H, Chen X F. Decadal climate characters and formation condition of flooding in south and droughts in north in China (in Chinese). Quart J App Meteorol, 2003, 14: 614-647

25 Hu H R, Qian W H. Identification of the northernmost boundary of the East Asian summer monsoon (in Chinese). Prog Nat Sci, 2007, 17: 57-65

26 Guo Q Y. Teleconnection between the drought/flood in northern China and summer monsoon precipitation in India (in Chinese). Acta Geogr Sin, 1992, 47: 394-402

27 Qian W H, Zhu Y F. Climate change in China from 1880-1998 and its impact on the environmental condition. Clim Change, 2001, 50: $419-444$

28 Yan Z W, Nicole P M. On the relationship between global thermal variations and the wet/dry alterations in the Asian and Afican monsoon areas (in Chinese). Acta Geogr Sin, 1995, 50: 471-478

29 Ge Q S, Zheng J Y, Hao Z X, et al. Some key characteristics of climate change in China during the last 2000 years. Sci China Earth Sci, 2012, doi: 10.1007/s11430-012-4370-y

30 Qian W H, Tang S Q. Troughs of global monsoon (in Chinese). J Tropical Met, 2011, 27: 594-600

31 Wang Y, Yan Z, Chandler R E. An analysis of midsummer rainfall occurrence in eastern China and its relationship with large-scale warming using Generalized Linear Models. Inter J Climatol, 2010, 30: $1826-1834$

Open Access This article is distributed under the terms of the Creative Commons Attribution License which permits any use, distribution, and reproduction in any medium, provided the original author(s) and source are credited. 